\title{
DESARROLLO DE HABILIDADES SOCIALES PARA ESTUDIANTES UNIVERSITARIOS DE ALTO POTENCIAL ACADÉMICO
}

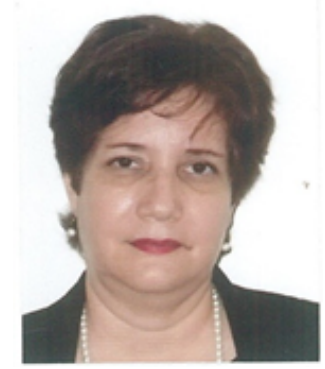

\section{Rosa María Aguirre Donadío}

Abogada, especialista en Derecho Civil Marítimo. rmaguirre@castillonieto.com

\section{RESUMEN}

Si usted ha escuchado hablar, alguna vez, de los “asesores de imagen”, sabrá que no sólo es viable sino que está de moda, que los adultos paguen a un "experto" para que les indique y les enseñe cómo deben vestirse, cómo deben hablar, moverse o reaccionar ante determinados estímulos. Sobre en el mundo de las artes y la política, esto es cada vez más frecuente, y lo que buscan los clientes del entrenamiento es convertirse en personas más simpáticas, más elocuentes y más convincentes. Qué tal si utilizáramos estas mismas armas para ayudar a estudiantes universitarios que necesitan de un entrenamiento especial para poder desarrollar todas sus habilidades innatas, superando sus miedos, traumas y complejos, con el objetivo de tomar el control de sus propias vidas, elevando, en el camino, su autoestima, mientras aprende a valorarse, a atreverse y a respetarse a sí mismo y a los demás. El presente escrito es un extracto de mi trabajo de Monografía para optar por el Postgrado en Docencia Superior. En él, se ofrece la idea de un curso para ayudar a estudiantes universitarios con un buen perfil académico pero con un desastroso perfil social.

Palabras clave: Curso Especial; desarrollar; miedos; frustración; auto-confianza; sociabilidad, confrontación; reingeniería; control; respeto; valores; atreverse.

\section{DEVELOPMENT OF SOCIAL SKILLS FOR UNIVERSITY STUDENTS OF HIGH ACADEMIC POTENTIAL}

\begin{abstract}
If you ever heard about people that hire another one called "expert" to teach them how to be more charismatic, powerfully and efficient with other persons, no matter if the process
\end{abstract}


include classes of how to dress, or speak, or walk or think, you will know that those courses are trend. Specially politicians and artist searched for it.

What about if we use the same strategic to teach some university students how to be more confidence, more brave and how to develop all their secrets talents, and moreover, how to increase their relations with other people. The present article is a resume of my written work for obtain the grade of university professor. In it, i am drafting an especial course to help university students whit a high escolar performance but with a terrible social behavior.

Key words: special course; to develop; fears; frustration; self-confidence; sociability; confrontation re-built; self-control; respect; integrity, braveness.

\section{PANORAMA}

Todos hemos conocido, alguna vez, a personas con un gran acerbo de conocimientos y con una mente ágil, pero con evidentes dificultades para interactuar socialmente. Estas personas, aunque en teoría deberían ser exitosas en sus respectivas profesiones, generalmente no lo son; y en el mejor de los casos, pasan desapercibidas o bien, son tachadas de inoportunas, impertinentes, molestas, torpes y hasta estúpidas.

¿Por qué sucede esto? ¿No debería cumplirse la premisa que dice que aquel que más sabe tiene mayores probabilidades de triunfar en la vida? ¿Acaso es mentira que, en nuestros tiempos, la información y el conocimiento equivalen a tener poder?

Ya sea que se trate de una paradoja o de una mutación social, la verdad es que resultan ser más exitosos aquellos que se saben manejar adecuadamente en sociedad y que tienen un instinto para detectar las necesidades afectivas de las otras personas, especialmente sus superiores.

La persona que, aunque no domine algunos temas, pero sabe decir las palabras adecuadas en el momento preciso; sabe alimentar el ego de sus superiores y reírse de sus chistes, seguramente tendrá garantizado no sólo un buen puesto de trabajo, sino también, un buen salario.

La sociabilidad es connatural al hombre, como bien lo decía Aristóteles ${ }^{1}$ en su obra La Política, y como tal, puede ser enseñada y aprendida. Y de aprender es precisamente de lo que trata la presente monografía. Este trabajo aboga por la creación de un curso especial, dictado en los centros de educación superior, para suministrar, a aquellos estudiantes, en principio, de A o B, que lo necesiten, ya sea voluntariamente o por recomendación de sus profesores, las reglas y modelos de conducta social que le enseñen a dominar el arte de la interacción y la improvisación; que desarrollen su personalidad y les permitan discernir entre lo que se debe decir y lo que no; lo que se debe hacer y lo que no; dependiendo de cada situación.

\footnotetext{
${ }^{1}$ Aristóteles: Filósofo griego, discípulo de Platón. Nació en el año 384 A.C. en Estagira, Macedonia. Ha sido el filósofo más influyente de la historia del pensamiento occidental.
}

ORATORES ISSN Impreso: 2644-3988 ISSN Electrónico: L-2644-3988 Año 8. Número 9. Diciembre 2018 - Mayo 2019 
Si somos el "Zoo Politicón" que mencionó Aristóteles en sus escritos, entonces no debería ser difícil despertar esas consciencias adormecidas y aletargadas. La estrategia consistiría en enseñar ciertas claves como postura, palabras, frases, miradas, gestos y actitudes; al comienzo, como si fuese un nuevo idioma que se está aprendiendo y luego, como el resultado de un análisis situacional con variables interdependientes. También se deberá enseñar cómo reconocerse y valorarse a sí mismo, y cómo interpretar asertivamente a los demás.

\section{ALCANCE DEL PROBLEMA}

Tomar decisiones puede ser fácil para algunas personas, pero medir las consecuencias de dichas decisiones y, sobre todo, sus repercusiones en el tiempo y en el espacio, son aspectos que, a menudo no suelen ser considerados adecuadamente. La planeación a mediano y a largo plazo no suele ser nuestro fuerte, probablemente porque no estamos acostumbrados a que las políticas de desarrollo sean constantes y perdurables. Muy por el contrario, los vaivenes gubernamentales de cada cinco años y la falta de compromiso institucional provocan que, en la mayoría de los casos, sólo logren concretarse los planes a corto plazo.

¿Que nos falta? Probablemente disciplina, organización, auto-control, resistencia, conocimientos específicos, identidad y valores, entre otros.

Pero, para ser realmente efectivos, no basta un conocimiento fugaz, producto de la lectura de los periódicos o de algunas revistas especializadas. Hace falta algo más: hace falta un fundamente teórico, una actualización internacional y una capacidad comprobada de análisis de perspectivas. La planificación detallada y el mantenimiento deben ser, siempre, componentes esenciales a la hora de realizar planes y presupuestos en cualquier campo de la vida.

Como recomendaba Platón ${ }^{2}$ en la antigua Atenas, en Grecia, en su obra La República y en otros Diálogos, "los más sabios y aptos son los llamados a gobernar y a dirigir." No importa si no nos agrada su apariencia, no importa si no visten a la última moda; lo importante es que tengan el conocimiento requerido, la experiencia, la habilidad y que sean capaces de realizar las conexiones abstractas necesarias para identificar la realidad de las cosas y trazar el camino para la realización de los planes hacia el futuro.

Adicionalmente, es vital, para el éxito de cualquier empresa, pública o privada, la existencia de principios y valores, claros y contundentes. Sólo así se podrá garantizar que las tareas establecidas o programadas se lleven a cabo sin contratiempos, y que el dinero o los recursos disponibles sean utilizados según lo planificado, sin separarse de los objetivos establecidos.

El éxito no sólo depende del plan; también depende de quién o quienes hayan de llevar a cabo ese plan; de su capacidad, su temple, sus convicciones y principios, mucho más allá de su mero carisma o facilidad para empatizar.

\footnotetext{
${ }^{2}$ Platón: Filósofo griego, discípulo de Sócrates. Nació en el año 427 A.C. Fundó La Academia, una especie de secta de sabios que se convirtió en el antecedente de las actuales universidades.
} 
Decía Maquiavelo en su inmortal obra El Príncipe, que "los hombres, en general, juzgan más por las apariencias que por la realidad. Todos los hombres tienen ojos, pero no todos tienen el don de entender lo que ven”. Siendo así, sería fácil manejar y utilizar a la mayoría de las personas, ya que, mareadas por la publicidad engañosa y las falsas libertades, que las inducen a perder su auto-control y a veces hasta su dignidad, no podrían ver ni entender más allá de sus necesidades físicas y emocionales inmediatas.

Tenemos el derecho de exigir que la o las personas que tomen las decisiones importantes para nuestra vida y nuestro país, sean las más aptas, las más experimentadas, las más nobles y las más honestas.

Reconozco que las habilidades sociales son imprescindibles en nuestro mundo, y que son muy afortunados aquellos que las tienen naturalmente. Pero me preocupa en extremo la suerte de aquellos que, por vicisitudes de la vida, no lograron desarrollar estas tan necesarias habilidades interactivas y, por tal carencia, ven amenazado el ejercicio de su profesión e, incluso, su existencia, a causa de la mediocridad, la impotencia y en no pocos casos, la envidia, la agresividad y la depresión.

Lo anterior es un oscuro panorama de desperdicio humano, de falta de visión y de mala utilización de recursos. ¿Por qué permitir que las capacidades de estas personas se truequen en sentimientos bajos, viles y autodestructivos? ¿Por qué no pensar en una forma de proporcionarles el conocimiento social y la práctica o experticia que les hace falta para hacer fructificar sus otros talentos $\mathrm{y}$, con ellos, destacarse en la sociedad?

\section{LA JUSTIFICACIÓN}

Estadísticamente, los estudiantes de nota "C" suelen ser mucho más exitosos que los estudiantes de nota "A". Ésto se debe a que mientras los estudiantes de "A" se mantienen enfocados en sus estudios, sacrificando en numerosas ocasiones sus actividades extracurriculares, los estudiantes de "C" no se sienten tan presionados y se permiten vivir otras experiencias, y como consecuencia comparten más con sus semejantes, lo que les hace ganar en aquello que, precisamente, constituye la carencia y la debilidad de la mayoría de los estudiantes de "A".

Enfocándonos en nuestro país, Panamá, en el Proyecto de Planificación Educativa actual del Ministerio de Educación (MEDUCA), el cual se inspira en la Declaración Mundial sobre la Educación Superior de la UNESCO ${ }^{4}$, se plantea la necesidad de un sistema educativo visto desde un punto de vista integral, que pueda llegar a aquellas poblaciones de difícil acceso y a aquellos grupos de personas con necesidades especiales.

¿Acaso no es una necesidad especial la carencia de habilidades sociales en futuros profesionales de alto potencial? Entendiéndose por alto potencial a estudiantes de A o B que evidencian una fuerza escondida que no termina de manifestarse ¿Acaso no debería

\footnotetext{
${ }^{3}$ Maquiavelo: escritor y filósofo del renacimiento, nacido en Florencia, Italia.

${ }^{4}$ UNESCO: Organización de Las Naciones Unidas para la Educación, la Ciencia y la Cultura.
} 
considerarse como una prioridad el suministrar a estas personas las habilidades que, en apariencia, la naturaleza o el medio ambiente en que crecieron no les han proporcionado? ¿Acaso no es deber del sistema educativo superior llenar esos vacíos incongruentes que repercuten negativamente e impiden el desarrollo pleno de los individuos?

Estas y otras preguntas son las que me propongo traer a la luz, para llamar la atención sobre un campo hasta el momento menospreciado. Un campo de altas repercusiones, pero que nunca ha sido visto como una necesidad educativa y que, menos aún, cuenta con el manejo debido. Quiero proponer una estrategia novedosa, que podría transformar muchas vidas de una manera efectiva y favorable.

Se puede decir que la Declaración Mundial sobre la Educación Superior así lo intuye, pues hemos encontrado en ella dos puntos de suma importancia para nuestro trabajo: en primer lugar, la diversificación como medio para reforzar la igualdad de oportunidades y, en segundo lugar, los métodos educativos innovadores, el pensamiento crítico y la creatividad.

Tenemos conocimiento de algunos autores que, planteando la misma necesidad apremiante de educar en sensibilidad, sociabilidad y valores, han promovido proyectos educativos pero centrados en la educación básica general. Autores como María Montessori ${ }^{5}$, Begoña Ibarrola ${ }^{6}$ y Baltazar Gracián ${ }^{7}$ son un distinguido ejemplo.

Sin embargo, nuestra propuesta es la de hacer extensivo el concepto planteado por los investigadores y docentes mencionados, a una población distinta: la población universitaria. Se trata de un problema que inicia en la niñez y en la adolescencia, pero si no se atiende a tiempo, se hace cada vez mayor. Por esta razón es menester ponerle un alto, en cualquier etapa de la vida, y qué mejor momento para efectuar un cambio radical que el período universitario.

\section{EL ORIGEN DE LA DEFICIENCIA.}

Buscar los recónditos orígenes de la incapacidad social en ciertos individuos de alto desempeño académico, intelectual y moral podría llevarnos por diversos caminos, algunos menos agradables que otros.

Esos orígenes pueden estar en un medio ambiente nocivo, con un padre o una madre extremadamente dominantes, agresivos o muy críticos; o, por el contrario, con padres muy ocupados e indiferentes a los sentimientos de sus hijos; o padres demasiado permisivos.

\footnotetext{
${ }^{5}$ María Montessori: educadora, científica y pedagoga nacida en Italia en 1870. Creadora del método educativo Montessori. Demostró que se podían desarrollar habilidades intelectuales, sociales y afectivas en niños y jóvenes con problemas de conducta.

${ }^{6}$ Begoña Ibarrola: docente, escritora y pedagoga española contemporánea. Creadora de un nuevo sistema de educación en las emociones.

${ }^{7}$ Baltazar Gracián: catedrático universitario, Jesuita. Nacido en Cataluña, España, en 1601. Pretendía dotar a las personas de los recursos que les permitieran defenderse socialmente.
} 
La incapacidad de interacción social también puede ser causada por un trauma, producto de un agente externo a la familia pero que, por falta de orientación, o por un orgullo mal encaminado, no recibió la atención requerida en el tiempo adecuado; o puede tratarse de un espíritu y una mentalidad diferentes, que generan en la persona una dificultad para entender la forma de comportamiento y de pensamiento de la mayoría de sus congéneres; o simplemente, puede ser la consecuencia de una cadena intergeneracional negativa, en la cual la conducta deficiente en términos sociales se ha transferido de una generación a otra, sin mayores alteraciones.

Por suerte, todas estas causas de la atrofia social pueden ser curadas, con la terapia y la reprogramación o reingeniería mental apropiada. No se trata de un mal físico, sino de una actitud equivocada hacia las relaciones sociales, en particular, y hacia la vida misma, en general.

Tanto en la reprogramación como en la reingeniería mental, la educación juega un papel preponderante: representa la ejecución del contenido de la nueva formación-reprogramación; y la metodología de dicha enseñanza podría ser entendida como una terapia, en razón de los efectos buscados.

No se requiere de medicinas, sólo de educación y entrenamiento; la ideal apertura a una nueva forma de ver y evaluar, de procesar y de encontrar perspectivas. Nuestra propuesta es humana, no científica. Se basa en la lógica, la comprensión y la empatía. Es una forma de enseñanza especial, para un grupo especial de estudiantes con necesidades particulares.

Durante el proceso, parecerá que se está enseñando a un niño pequeño a hablar o a caminar. No importa. Es parte del camino que hay que recorrer, debido a que estamos buscando crear una nueva vida para estos estudiantes, de entregarles, paso a paso, las llaves de la puerta hacia su propia liberación; porque un individuo aislado, que se siente incomprendido por el mundo que lo rodea, es un ser incompleto, infeliz y, por ende, no rinde al nivel de su potencial.

Cuando mencionábamos, en páginas anteriores, que los alumnos de "C" desarrollaban más su inteligencia emocional porque se daban el tiempo de compartir y experimentar, podríamos haber mencionado también que estos alumnos se permiten expresar libremente sus sentimientos y emociones, algunas veces en forma descontrolada, cometiendo errores y metiéndose en problemas, pero aprendiendo. Aprendiendo a conocerse, a establecer límites basados en su propia experiencia y, sobre todo, aprendiendo a manejar sus sentimientos y su libertad.

Los afectos y la forma como se expresan dicen mucho de las personas. En la espontaneidad versus la represión se manifiestan los rasgos de nuestra personalidad. Si bien todos los excesos son malos, los afectos y los sentimientos no pueden ser totalmente reprimidos, pues son energías connaturales al ser humano y tratar de ocultarlas sólo nos lleva a una desviación de esa misma energía, la cual, en lugar de exteriorizarse, es decir, de dirigirse hacia otras personas, para ser compartida, se queda dentro de quien la reprime 
y provoca pensamientos y sensaciones negativas que repercuten, más pronto o más tarde en la conducta de quien sufre este problema, lo que termina afectando, inclusive, a sus familiares y compañeros de trabajo.

Begoña Ibarrola ${ }^{8}$, en su libro Educar en las emociones es la clave para favorecer el aprendizaje, asegura que "la sensibilidad es de vital importancia en la vida de las personas". Si la persona no desarrolló completamente su sensibilidad, debido a que en algún momento se detuvo el proceso de madurez y, por lo tanto, de evolución personal, la vida de esa persona se verá permanentemente, de una u otra forma, afectada por esa circunstancia."

Nuestras acciones están determinadas por nuestros pensamientos; y nuestros pensamientos, a su vez, están condicionados por nuestra sensibilidad. Nuestra sensibilidad es el marco que nos delimita, para bien o para mal; consciente o inconscientemente; a veces de una manera evidente, otras veces, no tanto.

Por ello la importancia del "sano equilibrio", frase que aplica para todo lo que es realmente importante. Lograr que una persona sin equilibrio pueda transformar sus hábitos y comience a reconocer sus sentimientos, y a expresarlos sin auto-reproches, es el primer paso para una nueva existencia más saludable, más armónica y más plena.

Si el objetivo de la educación hoy en día es proporcionar herramientas para que los individuos y las sociedades logren alcanzar su máximo nivel, en todos los aspectos de su existencia; y si, realmente, la intención de los organismos internacionales como la UNESCO y de los gobiernos de los países miembros es la de proporcionar una educación universitaria integral "que permita el desarrollo de todas las potencialidades de los estudiantes en las diferentes esferas de su vida", entonces, el objetivo principal de la presente monografía es lograr que los centros educativos superiores reconozcan que tienen la obligación moral de ayudar a los inadaptados sociales a reencontrar su camino, libres de taras, cadenas, miedos, prejuicios, complejos y culpas.

\section{¿En qué consiste, exactamente, la incapacidad social?}

La incapacidad social no es fácilmente detectable en todas las situaciones. Muchas veces se le confunde con torpeza o con arrogancia, vanidad o desprecio hacia otros. Pero ciertamente, tanto la incapacidad social manifiesta como la no manifiesta o confusa, son ambas los extremos de una misma cuerda. Las dos producen insatisfacción, incomodidad y marginalidad. Ambas necesitan ayuda urgente.

En síntesis, los destinatarios del curso serían esos estudiantes que, por falta de confianza en ellos mismos o por una mala actitud, ni expresan ni llevan a la realidad sus múltiples ideas y así dejan pasar de largo muchas oportunidades. En otras palabras, va dirigido a quienes no saben cómo ser competitivos.

\footnotetext{
${ }^{8}$ Begoña Ibarrola: Docente, escritora e investigadora española. Creadora de los cursos para para docentes para educar en las emociones.
} 
El Dr. Georges Mauco', en su libro La educación de la sensibilidad en el niño, en el capítulo II, titulado "Las grandes etapas de la evolución afectiva del niño", expresa textualmente lo siguiente: "El carácter, la inteligencia y la actividad están condicionados por la sensibilidad de la primera infancia. Por ella el individuo, aún inconsciente, se pone en contacto con el mundo externo y ella teje los primeros vínculos entre el niño, los seres y cosas que le rodean. Esos lazos, egocéntricos al principio, es decir, encauzándolos todos hacia el sujeto, que se confunde con el mundo, debe evolucionar con la misma sensibilidad para conducir al altruismo del adulto normal."

Continúa diciendo el Dr. Mauco:

"Toda evolución es un renunciamiento continuo y lleva consigo una sucesión de nacimientos: no puede uno encaminarse hacia el porvenir sino renunciando al pasado, ni se descubren nuevas tierras de no consentir de antemano en perder de vista las costas antiguas. Para llegar al desarrollo adulto y adaptarse a él hay que superar situaciones muy penosas, y no todos lo consiguen por igual, porque ante una situación penosa para la sensibilidad existe, en cada uno de nosotros, cierta tendencia al retroceso afectivo. Estas fijaciones o retornos afectivos subconscientes constituyen verdaderos quistes y pueden persistir durante toda su existencia."

Podemos interpretar, del texto anterior, que algunas personas se restringen a sí mismas, sobre todo en su esfera social, por no poner en riesgo su sensibilidad, la cual se encuentra resentida por un trauma o suceso del pasado que no fue superado. Se trata de un mecanismo de defensa aparente porque, en realidad, juega en contra del propio individuo al no permitirle integrarse ni aceptarse, por miedo a salir lastimado en el proceso.

Ante este panorama, resulta necesario romper la barrera de la inactividad social y exponer al individuo precisamente a aquellas situaciones que más le atemorizan. El acompañamiento idóneo en este proceso es de vital importancia. Únicamente así se logrará que el inadaptado social inicie una nueva vida más placentera y fructífera, cumpliendo con lo que dice el propio Dr. Mauco": "Para lograr la propia liberación es preciso que cada uno vuelva a nacer por sí mismo". Entendiéndose por la frase "nacer por sí mismo" que el cambio sea producto de una toma de consciencia sobre la necesidad de dicho cambio y con pleno conocimiento y aceptación de sus resultados.

\section{PROPUESTA}

En el mercado abundan los libros de auto ayuda y de superación. Las técnicas para desarrollar la inteligencia emocional son por todos conocidas. Sin embargo, la inteligencia emocional por sí sola no es garantía de excelencia; necesita ser complementada por la humanidad, los valores y el conocimiento o destrezas, según el caso.

\footnotetext{
${ }^{9}$ Georges Mauco: autor francés. Director del Instituto Claude Bernard.

${ }^{10}$ Georges Mauco. La educación de la sensibilidad del niño. 1980. Madrid, España. Editorial Aguilar.
} 
La unión de la inteligencia emocional con la inteligencia en otros campos y los valores fundamentales da como resultado la combinación perfecta. Mientras que, por separado, son insuficientes.

Al respecto John C. Maxwell ${ }^{11}$, en su libro titulado "El talento nunca es suficiente", expresa, con claridad, lo siguiente: "Para la mayoría de las personas, el primero y más grande obstáculo hacia el éxito es creer en sí mismas. Una vez que las personas descubren cuál es su mejor área (el área donde ellas son más dotadas) lo que las limita no es la falta de talento. Es la falta de confianza en sí mismas, lo cual es una limitación auto-impuesta. No creer en sí mismo funciona como un techo sobre el talento. Sin embargo, cuando las personas creen en sí mismas, liberan un poder y recursos que inmediatamente las llevan a un nivel más alto."

Lo que deseamos es formar personas capaces, seguras, competentes, con iniciativa $\mathrm{y}$, al mismo tiempo, sinceras, justas, honestas y leales. La sociedad necesita personas que puedan decir "no" cuando lo amerite. Personas que tengan la suficiente humanidad para poder reconocer los derechos de los demás y respetarlos. Personas que sepan pensar, analizar $\mathrm{y}$ tomar las mejores decisiones. Personas con un amplio conocimiento del mundo, capaces de negociar y obtener excelentes resultados que beneficien a la mayoría.

El curso por el cual abogamos sería estrictamente presencial y debería durar, como mínimo, dos cuatrimestres, con asistencia mínima de tres veces por semana. Las clases serían prácticas, y la teoría se iría develando con cada actividad que se realice, de forma que los estudiantes estén expuestos, permanentemente, a la confrontación de sus miedos, con indicaciones o retro-alimentaciones oportunas acerca de lo que han hecho mal, y qué y cómo podrían hacer para mejorarlo.

La teoría acerca de cómo debería ser su actitud o su conducta en cada ocasión debe ir, siempre, unida a una dinámica pre-diseñada, de forma que los estudiantes puedan aprender de las tres formas conocidas: viendo, escuchando y haciendo. En algunas ocasiones, las dinámicas o prácticas podrán requerir salir del salón y desplazarse a otros escenarios. Pero, en todo momento, los participantes del curso deberán estar acompañados por su instructor o docente, quien les proporcionará la guía y el apoyo que sean necesarios hasta alcanzar sus objetivos.

La repetición constante, la confrontación, el estímulo, el apoyo y la guía, además de la retroalimentación sincera pero positiva, luego de cada reto, lograrán, al finalizar el curso, que el estudiante cambie la forma de verse y apreciarse a sí mismo y, en consecuencia, su manera de relacionarse con sus semejantes.

\footnotetext{
${ }^{11}$ John Maxwell: especialista en inteligencia emocional. Autor de numerosos best-sellers.
} 
Conocer las normas de conducta y de interacción social les proporcionará la seguridad para desenvolverse con naturalidad, propiedad y sin temor en cualquier circunstancia que la vida le presente. El acompañamiento y la guía sólo serán necesarios durante el curso, porque como estamos tratando con estudiantes inteligentes, al cambiar su actitud ante la vida, su cerebro comenzará automáticamente a procesar la información de una nueva forma, hasta el momento en que ellos mismos puedan tener el control de sus acciones, de una manera espontánea y agradable.

Los mejores y más acaudalados empresarios asistieron a escuelas de negocios donde les enseñaron a producir y administrar el dinero. Los estudiantes talentosos y sin dificultades para socializar son reclutados para asistir a cursos para líderes, en los que se les enseña a ser líderes eficaces en sus respectivos campos profesionales, y en sus correspondientes lugares de procedencia.

Lamentablemente, no todos los egresados de la educación secundaria tienen esas oportunidades. Por el contrario, muchos llegan a la universidad inmaduros, afectiva y socialmente; otros carecen de límites y parámetros; otros adolecen de falta de disciplina y concentración o métodos de estudio, producto de un sistema educativo de pre-media y media que requiere cambios urgentes.

Al respecto, el Dr. Camilo Cruz"12 nos dice en su popular libro La Vaca: "No debemos olvidar que todo lo que programemos en la mente determinará si triunfamos o si fracasamos. Las creencias, valores y convicciones que recojamos a lo largo del camino y reforcemos con nuestras acciones, forjarán la persona en la cual nos convertiremos. Tristemente, cuando la mayoría de nosotros nos graduamos de la escuela secundaria, ya hemos sido programados casi totalmente para la mediocridad."

En este sentido, si la escuela secundaria no pudo brindar una alternativa favorable al desarrollo de las habilidades de sus estudiantes, le corresponde a la universidad lidiar con este problema.

\section{PERFIL DEL DOCENTE DEL CURSO ESPECIAL PARA DESARROLLAR HABILIDADES SOCIALES EN ESTUDIANTES DE ALTA POTENCIALIDAD ACADÉMICA.}

El docente ideal para el curso que proponemos debe tener las siguientes cualidades indispensables: ser paciente, sensible, tolerante, compresivo, hábil, receptivo, recursivo, creíble, preferiblemente extrovertido y muy bien informado.

\footnotetext{
${ }^{12}$ Camilo Cruz: autor latinoamericano. Se especializa en libros para motivar el cambio de actitudes en las personas.
} 
Adicionalmente, deberá tener las competencias académicas propias de la docencia andragógica y de la materia que impartirá, a sus estudiantes; y no está demás decir, debe tener facilidad para interactuar con sus alumnos y con otras personas en diferentes contextos. Convendría también que el docente pudiese contar con el asesoramiento de personas expertas en psicología y en reingeniería social.

La formación académica del docente, preferiblemente, sería en psicología clínica, sociología, trabajo social, o en áreas relacionadas, siempre y cuando se evidencien dotes de buen desempeño y experiencia en manejo de grupos con cierto grado de dificultad.

El instructor de este curso especial deberá ser capaz de impartir sus enseñanzas tomando en consideración las diferencias de cada uno de los estudiantes, sin discriminar ni hacer sentir mal a nadie. La formación será grupal, pero con atención individualizada. La facultad de Psicología del centro de educación universitaria o de la coordinación correspondiente, deberá estar en permanente disponibilidad para el docente y para los estudiantes.

Es muy importante que el facilitador o docente tenga siempre presente que él es sólo eso: un instructor, y que no tiene la última palabra porque cada estudiante y cada caso es diferente del otro. El docente deberá tener muy claro que el día a día es el mejor consejero. Que en este curso no pueden existir reglas fijas de procedimiento, sino sólo objetivos por alcanzar. Y en el marco de todo lo anterior, los principios y valores serán los condimentos que le den el gusto distintivo al producto final.

Al terminar el curso, el nuevo comportamiento social de los estudiantes deberá fluir de manera natural, acompañado de un sentimiento íntimo de complacencia y satisfacción; un empoderamiento de su propia existencia y de su futuro, pero conscientes del valor de cada individuo, y sabiendo diferenciar entre los derechos propios y los ajenos. Recordemos que el ideal del género humano es transmutar el egoísmo natural de los primeros años en altruismo y natural convivencia con nuestros semejantes.

El pensamiento positivo los distinguirá y no tendrán miedo de enfrentarse a situaciones desconocidas o a personas intimidantes. Sus armas serán la razón, la propia seguridad o confianza en sus capacidades, el auto-control y la conciencia de ser diferentes y quererse como tales; así como el reconocimiento de la efectividad de sus nuevas destrezas. La fórmula: confianza + empeño + energía + equilibrio emocional, dará por resultado el éxito en cualquier empresa o acción que realicen.

El desperdicio indiscriminado del talento humano trae consigo graves consecuencias. Nuestras futuras generaciones merecen mejores promesas. Pero hace falta involucrarse, entender, querer ayudar y poner manos a la obra. Lo primero sería identificar el problema planteado de una forma certera, sin lugar a dudas, y partiendo de ahí, buscar las soluciones apropiadas, tanto privadas como públicas. 


\section{REFERENCIAS BIBLIOGRÁFICAS}

- Bosco J. (2005). Memorias para el Oratorio. Santa Tecla, El Salvador: Imprenta Ricaldone.

- Cherniavsky, A. y Sapia, P. (2006). Filosofía griega. Buenos Aires, Argentina: Editorial Sevagra. S.A.,

- Cruz, C. (2015). La Vaca. Nashville, Tennessee, Estados Unidos de América: Editorial Taller del Éxito, Inc.

- Cuyas A. (2007). Hace falta un muchacho. Panamá, República de Panamá: Editorial Géminis.

- Freud S. (1981). La interpretación de los sueños. Madrid, España: Editorial Alianza.

- Ibarrola, B. (2010). Cuentos para niños felices. País Vasco y Navarra, España.: Editorial SM, Biblioteca de Innovación Educativa.

- Maquiavelo, N. (1936). El Príncipe. Madrid, España: Editorial EspasaCalpe.

- Mauco, G. (1980). Educación de la sensibilidad en el niño. Madrid, España: Editorial Aguilar.

- Maxwell, John. (2007). El talento nunca es suficiente. Nashville, Tennessee, Estados Unidos de América: Editorial Grupo Nelson.

- Platón. (1983). Diálogos de Platón. Barcelona, España: Ediciones Orbis, S.A.

- Naciones Unidas. Declaración Mundial de Los Derechos Humanos. Artículo 26.

- UNESCO. La Declaración Mundial sobre la Educación Superior.

- Ministerio de Educación de Panamá (MEDUCA). 2014-2019. Plan Estratégico de Educación de Panamá. 